\title{
Glass Fibers: Quo Vadis?
}

\author{
Edith Mäder \\ Leibniz-Institut für Polymerforschung Dresden e.V., Dresden D-01069, Germany; emaeder@ipfdd.de; \\ Tel.: +49-351-4658-305 \\ Academic Editor: Stephen C. Bondy \\ Received: 16 February 2017; Accepted: 21 February 2017; Published: 24 February 2017
}

Since the early 1930s, the process of melting glass and subsequently forming fibers, in particular discontinuous fiber glass or continuous glass filaments, evolved into commercial-scale manufacturing. Most commonly, a direct melt process is applied. Thereby, the several raw materials were mixed, fed into a furnace, melted and forwarded to the fiber-forming units. Here, the filaments are formed by passing a bushing plate with a certain number of nozzles. Both the number of nozzles as well as its design may vary. Arrangements of 4000 or 8000 nozzles frequently occur. The bushing plate is the most important and expensive part of the machinery for glass fiber processing. The bushings are heated electrically and their temperatures are precisely controlled to maintain a constant viscosity of the glass melt. A high-speed winder catches the filaments at a circumferential speed, which is much faster than the molten glass that exits the bushings. Thus, a tension is applied to the filaments. The fiber-forming process is affected by the constitution and properties of the glass melt. Although glass fibers can even be made from strong viscous silicate melts, other ingredients are added to reduce the melting temperature and viscosity and impart other properties for specific applications. E-glass, originally aimed at electrical applications, with a composition including $\mathrm{SiO}_{2}, \mathrm{AI}_{2} \mathrm{O}_{3}, \mathrm{CaO}$ and $\mathrm{MgO}$, was further developed as a more alkali-resistant and high-performance alternative to the original soda lime glass in order to design environmentally and energy-friendly glass compositions [1]. Boron was also added via $\mathrm{B}_{2} \mathrm{O}_{3}$ to increase the difference between the temperatures at which the E-glass batch melted, or it was avoided, motivated by environmentally-friendly aspects. S-glass fibers, developed for higher strength, are based on a $\mathrm{SiO}_{2}-\mathrm{AI}_{2} \mathrm{O}_{3}-\mathrm{MgO}$ formulation but contain higher percentages of $\mathrm{SiO}_{2}$ for applications in which tensile strength is the most important property. AR-glass fibers (alkali-resistant) for applications in textile-reinforced concrete were developed by adding $\mathrm{Zr}_{2} \mathrm{O}_{3}$ or basalt fibers which became popular as glass fibers rich in iron-oxide with enhanced Young's modulus and temperature resistance compared to those of E-glass fibers. In the final stage of the fiberization, a chemical coating or sizing is applied. Sizing is typically added at 0.5 to $2.0 \mathrm{wt} \%$ and includes coupling agents, film formers and lubricants. The sizing constituents influence both filament tensile strength and strand integrity, cause the fiber to strengthen the adhesion at the interface depending on the resin chemistry, improve the resin wetting and the compatibility with the resin, if the filaments are used for composites.

Summarizing the present state, the basic glass fiber processing as well as the glass fibers, have changed by many refinements since its commercialization more than 80 years ago, especially due to two main drivers: (i) highly economic and energy-efficient processing; (ii) improvement of the performance of the products. Thus, the manufacturers continue to push forward on both tasks, especially in their pursuit of newer applications for glass fiber reinforced composites. Through numerous process and product innovations, a number of new manufacturers contributed to a worldwide structural composite reinforcements market of roughly 4 to 5 million tons per year. Glass fibers are the most common reinforcement used in the polymer matrix, currently accounting for $98 \mathrm{vol} \%$ of composites in the United Kingdom and European composites production [2,3]. 
In this Special Issue of Fibers, four publications (one full-length review and three original articles) are dedicated to the main tasks of the two development drivers mentioned above. Specifically, the advantageous improvement of the mechanical fiber properties has motivated further applications; the implementation of multifunctional effects, which could result in smart materials or composites' interphases, are to be considered for future research.

Initially, Thomason and colleagues [4], in the review entitled Glass Fibre Strength-A Review with Relation to Composite Recycling, describe, through a detailed review, the recovery and reuse of glass fibers from manufacturing wastes. First, they highlighted the production of $0.5-1$ million tons of glass fiber manufacturing waste [5], most of which is landfilled. Furthermore, about $70 \%$ of reinforcement glass fibers are used to manufacture thermoset-based composites, which produce about $15 \%$ manufacturing waste, which is difficult to recycle in an efficient manner. They report that a number of processes, preferably for thermal recycling, are available. However, nearly all recycled glass fibers suffer from issues such as deteriorated performance and insufficient cost competitiveness compared with pristine materials. The most critical technical challenge in the development of a glass fiber recycling technology is the $80 \%-90 \%$ drop in the performance. The authors review the available literature addressing the strength loss of glass fibers after thermal conditioning in the temperature range up to $650{ }^{\circ} \mathrm{C}$, which has to be employed in a composite recycling process in order to retain the glass fibers to reuse them as reinforcement fibers. As main research topics, strength loss; related physical and chemical changes in the microstructure of the fibers; the role of water and sizing; and research on strength regeneration of recycled glass fibers are addressed in the review. The authors discussed the need to reactivate the regenerated fiber surface in order to enable an adequate level of fiber-matrix adhesion strength required to obtain acceptable composite performance. The strength regeneration obtained with hydrogen fluoride (HF) is explained to be related to the removal of damaged surface layers and the modification of existing cracks. As a preliminary conclusion, they summarize that heat-treated fibers with HF treatment followed by silanisation resulted in composites with high levels of composite performance recovery. The authors also review their own work [6,7] on 'non-HF based (e.g., short treatment in hot $\mathrm{NaOH}$ solution and further application of a silane sizing) glass fiber strength regeneration treatment towards a cost-effective closed-loop glass fiber recycling technology'. It should be mentioned that this review highlights the available knowledge on the thermally induced strength loss in recycling of glass fibers, discusses some of the related phenomena, and presents the status of research, besides many open questions connected with surface flaws, glass fiber durability, repair of fiber surfaces and interphase built-up in composites.

The context of this Special Issue then changes direction, going from the mechanical properties of glass fibers and recycling issues towards another more non-conventional route. The paper by Förster and co-authors [8] reports the surface treatment by chemical vapor deposition (CVD) on basalt fibers without catalysts in order to initiate hierarchical carbon nanotube (CNT) architectures. Thus, it might also reveal recycling strategies and contribute to upgrading the properties of recycled basalt fibers. This paper is an interesting continuation of previous work based on glass fibers [9-12]; many sensor utilities have switched to highly sensitive multifunctional carbon nanoparticle systems that can implement non-conductive glass fibers with electrical conductivity and realize response properties. This advance has resulted in smart composite interphases, variations of the material properties, and stimulated response to changes in the external environment (temperature, strain/stress, relative humidity) for structural application. Despite its potential, the possibility of structural failure remains one of the most challenging tasks in making the new generation of materials based on glass fibers safer in materials science. The capability to stimulate CNT growth is an exciting feature which could open new application fields for basalt fibers if the mechanism behind it were better understood.

Continuing further, a paper on the potential application issue of glass fibers is touched upon by Illing et al. [13], who report the effects of hygrothermal aging on the Poisson's ratio of thin injection-molded short glass fiber-reinforced polyamide 6, which describes the ratio of transverse strain to tensile strain under uniaxial mechanical stress, and represents a major problem, especially 
in thin-walled automotive parts. The authors demonstrate that the Poisson's ratio is not a constant value in the composites, but depends on glass fiber content and glass fiber orientation. The values can vary in the range of 0.22 to 0.43 depending on the climate storage; the Poisson's ratio increases with longitudinal orientation and in the same proportion as it decreases with the transverse orientation of the fibers. In dry climate storage, only a slight decrease takes place, independent of the specimen thickness.

Finally, the fourth paper of this Special Issue by Funke et al. [14] considers the investigation of durability and performance issues when different glass and basalt fibers are applied as integral fibers in cement-based matrices characterized by alkali-activated binders in comparison with ordinary Portland cement concrete. Integral fibers of alkali-resistant glass, E-glass, basalt and carbon were compared and resulted in a significant increase of the three-point bending strength. However, the durability of E-glass and basalt fibers dropped significantly, whereas the alkali-resistant fibers and carbon fibers revealed a sufficient durability in the alkaline-activated binder matrix.

In summary, this Special Issue 'Glass Fibers' provides insight into the development of properties and discussion of cost performance ratios with regards to recycling strategies and surface modification in order to implement multifunctional effects on glass fibers as well as composite interphases. Besides these challenging research topics, many issues of glass fiber application, as exemplarily discussed in two papers, preferably as composite reinforcement, still remain unsolved and must be considered in future work.

Conflicts of Interest: The author declares no conflict of interest.

\section{References}

1. Wallenberger, F.T.; Bingham, P.A. Fiberglass and Glass Technology; ISBN: 978-1-4419-0735-6; Springer: New York, NY, USA, 2010.

2. Shuaib, N.A.; Mativenga, P.T. Effect of process parameters on mechanical recycling of glass fibre thermoset composites. Procedia CIRP 2016, 48, 134-139. [CrossRef]

3. Witten, E. Composites Market Report, Market Developments, Trends, Outlook and Challenges; The GRP-Market Europe (AVK): Frankfurt, Germany, 2016.

4. Thomason, J.; Jenkins, P.; Yang, L. Glass Fibre Strength-A Review with Relation to composite Recycling. Fibers 2016, 4, 18. [CrossRef]

5. Thomason, J.L. Glass Fibre Sizing: A Review of Size Formulation Patents. Blurb Incorporated 2015. ISBN 798-0-9573814-3-8. Available online: http://www.blurb.co.uk/b/6244662-glass-fibre-sizing (accessed on 10 February 2017).

6. Thomason, J.L.; Sáez-Rodríguez, E.; Kao, C.C.; Nagel, U.; Yang, L. ReCoVeR: Regenerating the strength of glass fibres thermally recycled from end-of-life composites. In Proceedings of the 20th International Conference on Composite Materials, ICCM20, Copenhagen, Denmark, 19-24 July 2015.

7. Yang, L.; Sáez, E.R.; Nagel, U.; Thomason, J.L. Can thermally degraded glass fibre be regenerated for closed-loop recycling of thermosetting composites? Compos. Part A 2015, 72, 167-174. [CrossRef]

8. Förster, T.; Hao, B.; Mäder, E.; Simon, F.; Wölfel, E.; Ma, P.-C. CVD-Grown CNTs on Basalt Fiber Surfaces for Multifunctional Composite Interphases. Fibers 2016, 4, 28. [CrossRef]

9. Zhang, J.; Liu, J.; Zhuang, R.; Mäder, E.; Heinrich, G.; Gao, S. Single MWNT-Glass Fiber as Strain Sensor and Switch. Adv. Mater. 2011, 23, 3392-3397. [CrossRef] [PubMed]

10. Gao, S.; Zhuang, R.-C.; Zhang, J.; Liu, J.-W.; Mäder, E. Glass Fibers with Carbon Nanotube Networks as Multifunctional Sensors. Adv. Funct. Mater. 2010, 20, 1885-1893. [CrossRef]

11. Zhang, J.; Zhuang, R.; Liu, J.; Mäder, E.; Heinrich, G.; Gao, S. Functional interphases with multi-walled carbon nanotubes in glass fibre/epoxy composites. Carbon 2010, 48, 2273-2281. [CrossRef]

12. Tzounis, L.; Liebscher, M.; Tzounis, A.; Petinakis, E.; Paipetis, A.S.; Mäder, E.; Stamm, M. CNT-grafted glass fibers as a smart tool for epoxy cure monitoring, UV-sensing and thermal energy harvesting in model composites. RSC Adv. 2016, 6, 55514-55525. [CrossRef] 
13. Illing, T.; Gotzig, H.; Schoßig, M.; Bierögel, C.; Grellmann, W. Influence of Hygrothermal Aging on Poisson's Ratio of Thin Injection-Molded Short Glass Fiber-Reinforced PA6. Fibers 2016, 4, 17. [CrossRef]

14. Funke, H.; Gelbrich, S.; Kroll, L. Durability and Performance of Short Fibers for a New Developed Alkali Activated Binder. Fibers 2016, 4, 11. [CrossRef] 